\title{
COMMUNITY MENTAL HEALTH: HEALTH BUDGETS IN A MULTIFACTORIAL CONTEXT
}

Giuseppina Ancona ${ }^{1}$, Eleonora Fulco ${ }^{2}$, Simone Marchese ${ }^{3}$

\author{
Department of Mental Health, Provincial Health Company of Agrigento (ASP), Agrigento, \\ Italy
}

Introduction In the last three years the Department of Mental Health of the ASP (Provincial Health Company) Agrigento (Italy) has become the protagonist of an attempt to change the cultural reality of mental health in its own territory, to ready local communities to overcome the prejudices linked to the stigma connected to psychiatric pathology through the implementation of an experimental project funded by the Sicily Region, the PON (National Operational Plan) 19.2. At the same time, the Department of Mental Health of the Provincial Health Authority (ASP) has experimented with the introduction of flexibility in care pathways for serious patients so as to pursue a model of integrated intervention combining the efforts public health, private social, citizens (training / work, residential care) in which public health continues to respect the responsibility and ownership of the service but is enriched with new human resources to promote patient citizenship itineraries.

All this is in order to prevent mental health problems, stimulate the inclusion and active participation of those suffering from mental health problems - recognizing the experience and skills of patients and caregivers as an essential basis for the planning and development of mental health services ${ }^{l}$.

The goal of the project was to reduce the isolation of psychiatric patients by adopting new methods that determined an economic saving and a higher quality in therapeutic results: tools within the Health Budget ${ }^{2}$. This is a qualitative and quantitative definition of tools of the economic, professional and human resources necessary to trigger a process aimed at restoring the centrality of the person with mental illnesses within their care system.

The catalyst for the process of change was a "multidisciplinary staff" (group of carers) composed of psychiatrists, psychologists, social workers, professional nurses operating in a specific area who, through a continuous process of training and co-visioning ${ }^{3}$ have acquired new knowledge, shared experiences, fears, difficulties and innovative choices.

Another important element in this challenge is the integration between patient and local community. Until a few years ago, interventions in mental health were aimed at passive subjects (patients) who were the recipients of therapeutic interventions designed by health care professionals and delivered to outpatient clinics.In the last twenty years we have worked to apply the provisions of the various Objective - Mental Health Protection Projects ${ }^{4}$. The Sicily Region has today adopted a model based on a greater awareness of the patient and on the possibility that he or she has an active role in decisions about their therapeutic project (recovery).

The new clinical model of recovery is "a profoundly and truly personal process of changing one's values, feelings, goals, capacities and roles. It is a way of living one's life with

\footnotetext{
${ }^{1}$ World Health Organization, European Ministerial Conference on Mental Health, Helsinki, Finland, January 12th-15th 2005, Declaration on Mental Health for Europe

${ }^{2}$ Righetti A., "Health budgets and community welfare", Laterza, Bari 2013

${ }^{3}$ The co-vision device is a clinical discussion group composed of peers in which there is no supervisor present

${ }^{4}$ Official Gazzette, Approval of Objective Project “Mental Health Protection" 1994-1996, n. 93 of 22/04/1994 and Official Gazzette, Approval of Objective Project “Mental Health Protection" 1998-2000 n. 274 of

22.11.1999
} 
satisfaction, hope and initiative, despite the suffering and limitations caused by the disease. It involves the recovery not only of a condition of greater well-being, but rather of a new sense of one's existence, which can be made to evolve beyond the catastrophic effects of mental illness " (William Anthony, 1993) 5 . According to community mental health and recovery models ${ }^{6}$, the patient, where they have the potential, must acquire a degree of selfdetermination that will allow them to make realistic choices about their health and take advantage of the treatment opportunities offered to them.

\section{The "National Operational Plan (PON) 19.2"}

This work refers to some actions contained in the P.O.N. - line 19.2, including the Health Budget. The goal of the article is to show and monitor, through action-research, the evolution of the clinical process in some patients with severe psychiatric diagnosis, over a period of eighteen months. All this is in order to highlight the greater therapeutic and economic efficacy of community care, compared to the "classic" one based mainly on a welfare model. The hypothesis of intervention is based on the use of the group and the Local Community ${ }^{7}$ as tools of change, (Staff Group, patient group, team group, family group). It is up to the multidisciplinary staff of the services to legitimize the patient in their role as an active element within the care process, so as to give them a social role allowing them to reactivate the momentarily lost potentialities and to learn new ones.

The main working tool was the use of the P.T.I. (Individualized Therapeutic Project) ${ }^{8}$. This is a document constructed by the clinicians working with the patient, but which must be discussed with the patient and their family. In the document are reported: the psychopathological diagnosis and assessment; the personal and social functioning of the individual, the objectives to be achieved, the tools and methods of intervention, the case manager, the necessary resources, the implementation times, the process and methods for monitoring and verifying results. Within the P.T.I. the psychopathological evaluation takes place using the Brief Psychiatric Rating Scale (BPRS) ${ }^{9}$ while the part related to personal and social evaluation contains the questions of the Camberwell Assessment of Need (CAN) ${ }^{10}$, an interview to identify care needs. A term of six monthis is scheduled to verify the results.

The executive project, "Regional and Intercompany Program for implementation of actions to protect mental health in adulthood programmed by PANSM for the Priority Area of Needs: Serious Persistent and Complex Disorders" was coordinated by a project manager and a management team and had the scope of intervention the strengthening the LEA (Essential Levels of Assistance) to protect mental health in adulthood, within the rehabilitation therapeutic programs provided for by the Strategic Mental Health Plan of the Sicily Region. The LEAs in this area do not refer to single services but to protocols for taking

\footnotetext{
${ }^{5}$ Anthony W., Recovery from Mental IIIness: The Guiding Vision of the Mental Health Service System in the 1990s, http://citeseerx.ist.psu.edu/viewdoc/download?doi=10.1.1.690.1878\&rep=rep1\&type=pdf 6 Ibidem and also Anthony, W. et al. . "Psychiatric Rehabilitation." Boston, MA: Center for Psychiatric Rehabilitation, Sargent College of Health and Rehabilitation Sciences. Boston, MA: Boston University. 2002 ${ }^{7}$ Barone R., Bruschetta S. , D'Alema M. L'inclusione sociale e lavorativa in salute mentale. Buone pratiche, ricerca empirica ed esperienze innovative promosse dalla rete AIRSaM, Franco Angeli, Milano 2013

${ }^{8}$ GURS (Sicily Region Official Gazette), Strategic Plan for Mental Health, June 15th 2012, pag. 37

${ }^{9}$ Overall J.E. , Gorham D.R., The Brief Psychiatric Rating Scale, in Psycological reports, 1962, 10, 799-812, Southern Universities Press 1962

${ }^{10}$ Phelan, M., Slade, M., Thornicrotf, G., Dunn, G., Hollway, F., Wykes, T., Strathdee, G., Loftus, L., McCrone, P. \& Hayward, P. (1995). The Camberwell Assessment of Need: the validity and reliability of an instrument to assess the needs of people with severe mental illness. British Journal of Psychiatry 167, 589-595
} 
charge, taking into account the particular complexity and multi-factorial nature of major psychiatric disorders.

The project involved the activation of 6 Multidisciplinary Staff (one for each territorial area of the ASP of Agrigento except for one) composed of at least 3 operators who had a total of:

- 16 patients, in possession of P.T.I., trained to become social facilitators for mental health with Health Care Workers Budget (forms of temporary work of a social-rehabilitation nature).

- 7 patients with P.T.I. included in the Health Budget "Temporary Family Foster Care" (Patients entrusted to families other than their own).

\section{Health budgets: Social Facilitation and Foster Care}

Social facilitators ${ }^{11}$ are people who have gone through a mental illness and who have reached awareness, empowerment and the ability to live with their own symptoms within their care pathway. Through adequate training and continuous updating, they have the possibility of transforming their own experience and their path of "disease and healing" into a resource for the help and and support of other users. The facilitator plays an important mediation role in communicating with the health team. The facilitator accompanies the user in the social network of the services the user needs, supports the user in training and / or work choices, helps plan the management of free time, supports the individual during the entire process of social reintegration, even supporting him/her in daily activities (shopping, cooking, keeping the house clean and safe, ...).

Temporary alternative care refers to the inclusion of a patient in an "other" family unit to live a life, although in a temporary form, characterized by ties and relationships similar to those that occur in a family. The most important element is that ordinary citizens take charge of the psychiatric pathology together with the clinical staff, contributing to the spread of a community mental health. At the same time the patient plays an active role choosing their course of care; he or she is considered to be equal among the various other figures involved in the project.

\section{The Action - Research}

The study was carried out in the form of research-intervention, in a circular process between knowledge and transformation of reality, whereby the theory directs the action addressed to change and the effects reorganize the knowledge learned. Lewin defines intervention research as "Studying things by changing them (intervention) and seeing their effects (research)" ${ }^{12}$.

The objective is therefore to study the phenomena while changing them. The experimental nature of the interventions underlying the implementation of individualized projects has determined the need to monitor and evaluate, during the same 18 month period, two different clinical processes of P.T.I. pertaining to two different project actions: the Social Facilitator Users Project and the Temporary Family Foster Care Project. The two projects will be described below separately.

As for the first one, the Social Facilitators in Mental Health Project, the multidisciplinary clinical staff adhered to the idea that selected patients, adequately trained and supported by the services they belong to, could assist operators in managing one or more patients with some deficits in personal and social functioning, becoming a resource for

\footnotetext{
${ }^{11}$ Barone R., Duca R., Leonardi R, Auteri M.Y., Pezzano R. FACILITATORE SOCIALE: il supporto fra pari in salute mentale, Nuova rassegna di studi psichiatrici, Rivista on line di psichiatria Volume 17, 3 settembre 2018 http://www.nuovarassegnastudipsichiatrici.it/index.php/numeri-precedenti/volume-17/facilitatore-sociale-ilsupporto-fra-pari-in-salute-mentale

12 Lewin K. (1948), The child in the social environment, La Nuova Italia, Florence, 1967 
services and local communities. Sixteen patients were selected for the project: 14 were trained and 13 of them benefited from work grants lasting 6 months. The 13 patients who undertook the path of the Job Grants belonged to the Care Paths with the diagnosis of: Schizophrenic Disorder (4), Bipolar Disorder (4), Severe Personality Disorder (1) and Schizoaffective Disorder (1). From the analysis of P.T.I. it emerged that all the selected patients were characterized by a stable clinical picture with good conditions of compensation, good relational and social performances and a stable therapeutic compliance. All the phases of the project were periodically monitored. In the phase preceding the training and during the training there were monthly meetings with the multidisciplinary staff and with the facilitator users; after the training there were regular meetings with the health services to plan the start of the actions. During the realization of the work grants there were meetings of the co-vision group composed of user facilitators and two operators of the Department of Mental Health. At the same time, monitoring was carried out at the mental health services to define, in agreement with the facilitators, the projects started and monitor the clinical progress of the patients who were followed by the facilitators.

The projects assigned took into account the possibilities offered by the services, the users' predispositions and the clinical evaluations made by the service operators. In most cases the facilitators were assigned a user already in charge of the DSM. Among whose objectives present in their P.T.I. there was improvement in the management of daily activities, knowing how to use the resources offered by the territory and the community, and improvment in the level of personal and social autonomy. In other cases the facilitators were employed within the services to organize workshops aimed at other users, starting from the skills possessed by the patient facilitators.

To assess the outcome of the clinical processes that were performed during the 18 months of observation, a questionnaire was prepared with a re-test 4 months after the test, aimed at patients with work grants as well as a questionnaire to be given to the operators of the services.

From the quantitative and qualitative analysis of questionnaires addressed to patients, a vision of themselves and of the work they carry out emerges, characterized by the development of a greater capacity of empowerment linked, on the one hand, to the acquisition of greater skills related to the work of facilitator, to a greater self-awareness. These elements make patients more capable of coming into contact with themselves, with regards to their own abilities and potential, as well as their own limits.

These elements contribute to a greater perceived self-efficacy that makes them even safer in relationships with each other. Above all from the relationship with the operators and with their own mental health service they acquired the security that makes them feel "protected" even in their work as facilitators. These factors, of course, do not totally shield people from the difficulties that any job implies but which, at present, they are able to cope. The re-test questionnaire also highlighted the reduction of the idealized expectations that emerged from the beginning of the project and which were constantly worked on in the moments of co-vision.

The second project, a Temporary alternative Care Project, involved 7 DSM users. The 7 patients who undertook the project path presented the following diagnoses: Bipolar disorder, Paranoid schizophrenia (3), Schizophrenic psychosis, Schizoaffective disorder, Bipolar disorder, mixed episode, severe, with psychotic behavior.

The patients involved in this project had a clinical picture characterized by greater severity in the impairment of interpersonal skills and autonomous management of daily activities. Then, the selection of patients took place using the following criteria: poor social functioning, the presence of difficulties in adapting to changes, poor self-care, poor autonomy in daily 
management, low self-esteem. All these aspects that, in the past, would have induced medical personnel to institutionalize patients, with an economic burden on the community and isolating them from it.

The evaluation of clinical processes took place through a questionnaire, addressed to multidisciplinary staff, with 7 closed-ended questions and 3 open-ended questions. In the former, an attempt was made to assess the quality of the relationship between foster family and the patient entrusted, the relationship between both with the service and possible improvements for patients. In the latter, respondents were asked to indicate the critical points of the project and the areas in which the improvements of the patients occurred.

The answers to the questionnaire highlighted the importance of the foster family in increasing patients' sense of confidence, improving self-esteem, restoring relational skills and improving self-care, also thanks to an understanding of the nature of their own role of support and accompaniment. The services played an important role, representing a catalyst and a point of reference for a foster family and the patient entrusted. In a field test six months later, patients showed greater stability in the clinical picture and an evolution in personal and social functioning: greater personal care, trust in the operators, improvement of daily performance with more care in the environments of life. The foster families represented a real transformative flywheel and placed the patient-citizen within the community. Patients experienced healthy relationships and the foster families have played a mediating role between the patient and the local community.

\section{Conclusions}

In conclusion, it can be stated that the Community P.T.I., undertaken by multidisciplinary staff, patients and citizens, is not intended as a linear process but as a complex path that involves small steps, failures and successes, respecting individual differences, of the specific life stories, of the diagnostic picture, of the personal and social functioning level of the patient and of the degree of inclusion. In most cases, during the observation period, the patients involved in the research showed a greater capacity to manage their moments of difficulty and crisis. They were better able to give themselves the right time to "get back on track" and start again. Participants gradually acquired a new role that no longer coincides exclusively with that of "patient", but has also diversified according to the expansion of their own interests and life goals. The growth in empowerment level has also translated into a greater spirit of initiative both in personal daily contexts and in the relationship with mental health services operators and with the community itself. All this does not coincide with the patient's clinical recovery but certainly with the acquisition of "a new sense of one's existence, which can be made to evolve beyond the catastrophic effects of mental illness" 13 and it is "the being part" of a social context that demonstrates how the full involvement of the community represents the multifactorial response to mental distress ${ }^{14}$. The project, in fact, led the operators to think of themselves in a totally different way than in the past; it forced them to reconsider roles (their own, that of patients and that of family members), to rethink the organization of services and to reformulate the therapeutic-rehabilitative offers ${ }^{15}$. This has cracked the certainties, albeit crystallized, that characterize routine work to embrace, often and willingly, doubt, uncertainty, fear of making mistakes, and frustration. As it is easy to imagine all this

\footnotetext{
${ }^{13}$ Anthony, W. A., Cohen, M., Farkas, M, \& Gagne, C. (2002). Psychiatric rehabilitation, 2nd edition. Boston, MA: Boston University, Center for Psychiatric Rehabilitation

${ }^{14}$ Barone R., Bruschetta S., Frasca A. La ricerca sui gruppi comunitari in salute mentale. La valutazione clinica delle reti sociali e la psicoterapia di comunità orientata alla recovery, Franco Angeli, Milano 2014

${ }^{15}$ Barone R., Bellia V., Bruschetta S, Psicoterapia di comunità. Clinica della partecipazione e politiche di salute mentale, Franco Angeli, Milano 2010
} 
has represented a great effort that is still underway because those who really decide to question themselves are "condemned" to do so always, otherwise sooner or later they fall back into the crystallization of certainties that, although reassuring, flatten thought. Kahn 1617 pointed out that the perception of meaning by employees towards the task performed is an important driver for engagement. According to the author, in fact, the perception of meaning can be achieved through the assignment of challenging and varied tasks.

Having first crossed this "minefield" has allowed operators to more effectively transmit to patients the message proposed by the concept of recovery: the activation of a process aimed at building a way of life based on a sense of self- efficacy, free from the control of health institutions and tending to the exercise of one's life potential, which however is not free from hitches, errors, falls, etc., like any human event. But the staff members have also shown that if the services no longer have to have a rigid control over the patients, they can however continue to represent a professional and human support in the realization of the patients' life project.

The inclusion of patients in the world of work and in hetero-family contexts, in collaboration with the Local Authority and the third sector who shared training programs, P.T.I.s and operating practices with mental health services, contributed in fact to the different perception that society has of a psychiatric patient: not just a patient to be assisted but a citizen with needs and resources. "The answer to a disability is not a bed, it is rehabilitation"18. "Rehabilitation does not mean having a protected structure but involves reconstructing the contractual nature of the people so that they can re-enter the circuit of sociality" 19 .

The launch of the actions envisaged by the project, whose financing is limited in time, requires an even wider cultural change to ensure that these devices become an integral part of the rehabilitation tools also at the level of an enlarged community. In this sense the work that involves the awareness of Local Authorities and operators of the Third Sector is still ongoing and will involve the writers and all the operators of the ASP of Agrigento involved in the project.

\section{Bibliography}

- Anthony W., Recovery from Mental Illness: The Guiding Vision of the Mental Health Service System in the 1990s, http://citeseerx.ist.psu.edu/viewdoc/download?doi=10.1.1.690.1878\&rep=rep1\&type= pdf

- Anthony, W. et al. . "Psychiatric Rehabilitation." Boston, MA: Center for Psychiatric Rehabilitation, Sargent College of Health and Rehabilitation Sciences. Boston, MA: Boston University. 2002

- Anthony, W. A., Cohen, M., Farkas, M, \& Gagne, C. (2002). Psychiatric rehabilitation, 2nd edition. Boston, MA: Boston University, Center for Psychiatric Rehabilitation

\footnotetext{
${ }^{16}$ Kahn WA. Psychological conditions of personal engagement and disengagement at work. Acad Manage J 1990; 33: 692-724

${ }^{17}$ Kahn WA. To be full there: psychological presence at work. Hum Relat 1990; 45: 321-49

${ }^{18}$ Saraceno B., Towards an inclusive and participatory Mental Health, Report Open lecture, 15/05/2019, http://www.sportellotiascolto.it/salute-mentale-inclusiva-e-partecipata-report/

19 Ibidem 
- Barone R., Bellia V., Bruschetta S, Psicoterapia di comunità. Clinica della partecipazione e politiche di salute mentale, Franco Angeli, Milano 2010

- Barone R., Bruschetta S., D’Alema M. L'inclusione sociale e lavorativa in salute mentale. Buone pratiche, ricerca empirica ed esperienze innovative promosse dalla rete AIRSaM, Franco Angeli, Milano 2013

- Barone R., Bruschetta S., Frasca A. La ricerca sui gruppi comunitari in salute mentale. La valutazione clinica delle reti sociali e la psicoterapia di comunità orientata alla recovery, Franco Angeli, Milano 2014

- Barone R., Duca R., Leonardi R, Auteri M.Y., Pezzano R. FACILITATORE SOCIALE: il supporto fra pari in salute mentale, Nuova rassegna di studi psichiatrici, Rivista on line di psichiatria Volume 17, 3 settembre 2018 http://www.nuovarassegnastudipsichiatrici.it/index.php/numeri-precedenti/volume17/facilitatore-sociale-il-supporto-fra-pari-in-salute-mentale

- GURS (Sicily Region Official Gazette), Strategic Plan for Mental Health, June 15th 2012, pag. 37

- Kahn WA. Psychological conditions of personal engagement and disengagement at work. Acad Manage J 1990; 33: 692-724

- Kahn WA. To be full there: psychological presence at work. Hum Relat 1990; 45: 321-49

- Lewin K. (1948), The child in the social environment, La Nuova Italia, Florence, 1967

- Official Gazzette, n. 93 of 22/04/1994

- Official Gazzette, n. 274 of 22/11/1999

- Overall J.E. , Gorham D.R., The Brief Psychiatric Rating Scale, in Psycological reports, 1962, 10, 799-812, Southern Universities Press 1962

- Phelan, M., Slade, M., Thornicrotf, G., Dunn, G., Hollway, F., Wykes, T., Strathdee, G., Loftus, L., McCrone, P. \& Hayward, P. (1995). The Camberwell Assessment of Need: the validity and reliability of an instrument to assess the needs of people with severe mental illness. British Journal of Psychiatry 167, 589-595

- Righetti A., "Health budgets and community welfare", Laterza, Bari 2013

- Saraceno B., Towards an inclusive and participatory Mental Health, Report Open lecture, 15/05/2019, http://www.sportellotiascolto.it/salute-mentale-inclusiva-epartecipata-report/

- World Health Organization, European Ministerial Conference on Mental Health, Helsinki, Finland, January 12th-15th 2005, Declaration on Mental Health for Europe.

Keywords mental health, community, health 